\title{
An Analytical Study of Ideally Inherent Operative Transformation of the Original Mental Process in Edmund Husserl's Phenomenology
}

\author{
Phramaha Somphong Unyo \\ Asst. Prof. Dr. Lecturer, Mahachulalongkornrajavidyalaya University, Thailand \\ Somphong.uny@mcu.ac.th
}

\begin{abstract}
This research paper entitled "An Analytical Study of Ideally inherent Operative Transformations of the Original Mental Process in Edmund Husserl's Phenomenology" has three objectives: 1) to study the mental process of reflection and modification in which that mind is directed towards the intended object including the mental objects regarding Western philosophical thought, Edmund Husserl, 2) to study of the way to operative transformation of original mental process and, 3) to analyze various forms of transformed reproduction and a problem of the reproduction. It is found that the transformation of the original mental process in Edmund Husserl's phenomenology is the ideally inherent process of reproduction of mental process in which the mental process passed through the modificative process together with its contents so as to produce a novel knowledge. The transformative process as such is systematically operated with main following aspects: (1) The mode of giveness (the immanent essence of a concrete sensation-content such as a visual sensation-content in the field of visual sensation-Data that is continually adumbrated from the visual physical objects), (2) the temporal mental processes are to be unified as one stream of mental process, (3) the phase or the temporal horizon which is cosmic time in other ways such as horizon of Now, horizon of Before, and horizon of After, and (4) pure ego, the function of which is to direct its regards to the temporal modes of giveness (immanent essences). By its transformative operation, it is effectively proceeded with three steps. The first is a step of a physical perception of the mental process in which the perceived physical things is used as an essential content for all mental process as they are kept in a memory. The second step is succeeded from the first step which is called a retention or a primary memory; the process of a modification using the immanent object kept in a retention as the initial part of the constitution of an identical object. Then, comes the third step which is the step of a recollection or a second memory; it is to recall the remembered or represented for the perception again. After the whole process has fully accomplished, the remembered or represented is afresh reproduced. However, the reproduction of the remembered or the represented can emerge with two possibilities; one is the vague-reproduced information as without repeating while looking at the reproduced flash; other is afresh one as it is repeated resulting in further perception. However, the reproduction of the remembered can be accurate and perfect depending on two conditions; one is the condition of the perception of physical things and the condition of either clarity or obscurity of the whole object that is re-presented with the mode of mental process.
\end{abstract}

Keywords

Analytical Studies, Inherent Operative Transformation, Original Mental Process, Phenomenology

Article Received: 10 August 2020, Revised: 25 October 2020, Accepted: 18 November 2020

\section{Introduction}

In Husserl's phenomenology, one of essential points is a mental transformation in which mental process immanently functions under its stream together with the hyletic data such as the data of color, data of tone, data of smell, data of point etc. so as to reproduce a new information. However, this transformative process is to start with the originally mental process that is the material perception (perception of physical things), the perception of bodies. Therefore, it is said as the ideally inherent operative transformation of the ordinal mental process. The essential process of the transformation is the process of reflective act of mind and its modification as it is the initial operative process of mind functioning of transformation thereby functioning in the mode of seizing upon the essence of something immanent and also of experiencing something immanent. Then, mental process modifies whatever reflected immanently through duration of original course together with different forms of reproductions. In the process of the transformation, actually, it is said to be that the inherent operative transformation of ideally original mental process is the process of unifying a form of all mental process within one stream of mental process of pure ego in which mental process functions with the following aspects: (1) The mode of giveness (the immanent essence of a concrete sensation-content such as a visual sensation-content in the field of visual sensation-Data that is continually adumbrated from the visual physical object, (2)the temporal mental processes are to be unified as one stream of mental process, (3)the phase or the temporal horizon which is cosmic time in other ways such as horizon of Now, horizon of Before, and horizon of After, and (4) pure ego, the function of which is to direct its regards to the temporal modes of giveness (immanent essences). All of these aspects operate through various forms of the transformation which consists of:

1) Perceiving form of the physical objects which is said to be the original mental process in the transformative process,

2) Modificative form of retention which is called the primary memory succeeding from the original mental process,

3) Modificative form of recollection which is called second memory succeeding from the retention modification and,

4) Reproductive forms of all contents of mental process.

All of these forms are systematically transformed by succeeding from each other, from the original

mental process to retention, recollection and reproduction respectively. 


\section{Original Mental Process and Perceiving Process of the Physical Objects}

The original mental process is the mental process functioning of perception of the physical things that Husserl used as a starting point for the process of the inherent transformative operation of the mental process. More significantly, he illustrates the perception of the physical things of the original mental process closely connected with the forms of modification that are all rememberings, presentations in phantasies, and so forth. Regarding the perception of physical things of the original mental process, it said that it is external perception in other ways. In the process of physical perception, the perception can be fully accomplished with the essential factors:

1.The original mental process and pure ego,

2.Sensory organ or living body,

3.The physical things and sense contents,

4.The Reflection and intention.

With regard to perception of physical things of mental process, the physical things which are to be perceived will be the things with the objectivity and the valuable. With this, ego can direct its regard toward the objects in as far as the objects appear with a dual sense; the objectivity of the thing and valuing of the thing. Husserl explains such this essential of the objects with dual senses that not merely the thing of the objects we are intentionally directed out regard toward to but their value. As the objects appear not merely as a thing but with their qualities such as the value etc., in the act of valuing of the objects, we are directed to the valued; in the act of gladness, to the gladsome; in the act of loving, to the loved; all of these can be called "sense contents" in other ways. In this regard, when we are turned valuingly to a thing, we seize upon not merely a thing, but rather its valuable thing or the value

As for reflection and intention, both of them are essentially an immanent factor of mental process for knowing act of the objects thoroughly as it functions for noticing on the multicity of the objects resulting in opening up all angle of the objects. Husserl demonstrates the way to the reflective conduct thereby observing the objects covering all their appearances and contents thoroughly, "I see thing here at one from this side, then and even in continually changing manner from other side and ever new sides, that I am continually directly noticing it, this same thing and yet notice now these, now those chrematistics of the surface, or of the inside of something that opens up etc." So, it is to say that by only a reflection we can immediately direct a regard toward the multiplicity of the objects and results in the act of intuition or in the act of thinking consequently.

In perceiving objects, it is to perceive straightforwardly as the objects stand before perceiving eyes. In this way, the perceived objects are believed to be directly given. Although, the objects appear to perceiving organ at the same way, the organs function in perceiving the object in different ways as each of them has different functions. In this point, Husserl elucidates the process of perception as such by saying: "In seeing, the eyes are directed upon the seen and run over its edges, surfaces, etc. When it touches objects, the hand slides over them. Moving myself, I bring my ear closer in order to hear."

So, mainly, the possibility of physical perception as the original mind of the perception depends on four essential components: 1) qualities, 2) relationship, 3) changes, and 4) interaction of the perceiving objects.

Having perceived with original mental process, the perceived objects such as a tone, a color, or the contents such as a tone-unity, a color-unity, a tactile compel which is called "sensuous contents" endure and change in the duration or the temporal phase of the mental process. To put it more precisely in this point of views, the physical objects which are outwardly perceived continually relate to the temporal phase of the mental process in which the mental process flows under its stream and is permeated by the fact that the mental process relates itself to the objects. With this, Husserl precisely explains an essential relation between mental process and its objects that it is the essential characteristic of every act of mental process. In the modificative process, this perception with its enduring and changing has its modification within other forms of experiences. So, the perceived objects do not disappear in anywhere, but they are still kept in memory called "retention".

\section{Modificative Form of Retention (the Primary Memory)}

The modificative process of mental process relies on the contents kept in mind after perceiving outwardly; it is called "immanent evidence" or "memory". Only this evidence is constantly used as a vital evidence throughout the process thereby flowing under the mental stream towards each temporary time phase in the mental process. Husserl indicates the significance of memories in the immanent sphere that it can be memories of the past and future, but belongs to an essence of the memory that what is remembered has a location in relation to the actual present. Regardingly, mind functioning with its immanent evidence in this way is said to be a turning point for the modificative process resulting in reproducing a novel knowledge.

The memory or immanent evidence as such used immanently as a starting point for an information of the mental process of the modification is called primary memory or retention in other ways. The information in retention has a continual succession; from something external to something immanent and something immanent to retention.

The first is about the physical things perceived as an external perception; it is the perception in the case of consciousness of an external object denoting the external appearance as an immanent object. With this, Husserl puts three aspects of them respectively:

1. The appearance of something external,

2. The constituting consciousness in which the appearance of something external becomes constitutes as something immanent;

3. The turning-towards, which can just as well be a turning towards the appearance and its components as towards what appears. 
The second is about an immanent object to retention; it is to gather what immanent is together in

its continuity in the now-point. By this, Husserl illustrates the retentive constitution with an information from inner perception that:

1) The internal consciousness of the unitary immanent object, consciousness that is on hand even without turning towards the object, namely, as the consciousness that constitutes what is in time; either

2) the consciousness of something internal together with our turning towards it.

To put it more precisely in terms of modificative forms of retention or first memory, temporal objects can be continually succeeded to retention as they are not merely unities in time but contain a temporal extension in themselves. Husserl gives an example of a tone, each tone has its temporal extension itself; for example, the first tone sound, then comes the second tone, then the third and so on. In the process of changing of the physical objects, it is related to the temporal phase of the mental process that is from Now-phase to ever new Now- phase respectively. This signifies that the tone continually changes; it changes with its duration phase. When the tone is presently heard, it said to be Now-phase of the tone. After hearing, the tone recedes into memory, it is said to be the new Now- phase of the tone.

By constituting the immanent temporal objects to retention, it inherently dials with the immanent objects, which take the tone purely as a hyletic datum. Husserl uses primary impression as the source points as the beginning. By this, it is consciousness in a state of constant change with tone that the tone-now present "in person" continuously changes in something that has been: an always new tone-now continuously relieves the one that has passed over into modification. Here come to the primal impression, the consciousness of the tone-now passes over into retention. Then, this retention itself has in turn become a now-tone; it is something actually existing More importantly, it says that each retention is a continuum and each of them changes in succession from each other; each early is retention for every later point. It is called the continuity of retentive modification which has two aspects:

1. The first continuity emphasizes that the running off modes of an immanent temporal object has a beginning, a source-point, so to speak. It is running-off mode with which the immanent object begins to exist.

2. The second continuity is obviously included in the first, the continuity of running-off mode of the object's duration. It is the running-off continuity of enduring that a continuum whose phases are the continua of the running-off mode belonging to the different time-points of the duration of the object.

So, there are two kinds of retention; one is the retention resulting from the physical perception and other is the retention coming from immanent temporal objects.

\section{Modification of Recollection (The Second Memory)}

The object receded into deeper memory, a tone, for example, if it is to be directed to the process of perception in the present time again, must be recalled as the main aspect of recollective process is to uncover the past that Husserl said, "In the most original manner conceivable, it uncovers my own past by means of recollections." Recollection is said to be the secondary memory which proceeds after the primary memory, the retention, is already done. According to Husserl, a recollection absolutely differs from a retention in the way that the retention is something intuition of something absent; something which is not actually exist but has just existed and receded in past; by contrast, recollection is a re-presenting intentional act directed toward a completed past occurrence. So, Retention and Recollection are totally different in the terms of duration phases and functions; though, both of them function in relation with each other as they are in memory. Besides, precisely, Husserl gives more details of the different character of both recollection and retention, "We characterized primary memory or retention as a comet's tail that attaches itself to the perception of the moment. Secondary momentary, recollection, must be distinguished absolutely from primary memory or retention after the primary memory is over with, a now memory of this motion, of that melody, can emerge retention."

More importantly, the objects be recalled perfectly are a remembered and re-presented present and a remembered and re-presented past, so, recollection can be considerably classified into two aspects:

1. It is the presently and originally constituted recollection,

2. It is just past recollection.

In the recollective process, there are three aspects on which the recollection is accurately built:

1. A continuum of primal data,

2. A continuum of retentions,

3. A Union with them constitutes (or rather: reconstitutes) an immanent or transcendent enduring objectivity (depending on whether the recollection is directed towards something immanent or towards something transcendent).

With this, Husserl explains with the example of the case of melody we recall that we recently heard at a concert. The process of such this recollection of the melody is not different from the perception in general. With this, to recall perfectly and accurately, the whole memory phenomenon and the perception of melody should have exactly same constitution that is the point of now-point of perception corresponds a now-point of the memory. By this, we run though the melody in phantasy; we hear, as it were, first the initial tone, then the second, and so on respectively. The preceding tone is till kept in consciousness and then there is always the tone of now-point at particular time. It said that primary memory (retention) of the tone that, as it were, we have just heard and expectation (protention) of the tone that are yet to come fuse with the apprehension of the tone that is now appearing and that, as it were, we are now hearing. Then, the melody is re-presented (recalled).

Again, with the recollective process, the melody being recalled consists of two phases. The first phase is the 
actually hearing of melody. In this case, the melody itself as the temporal object is perceived; it is called present melody. The second phase is a just melody. It is about melody died away, and no longer being perceived as present; but it is still kept in consciousness.

\section{Reproduction's Mode of the Accomplishment}

The succeeding process from recollection or re-presentation of the modification of the mental process is reproductive mode. Having recalled the remembered, re-presented present and past of the objects, it said that the recollection such as can considerably establish various forms of an accomplishment; one is the reproduction of a flash and other is afresh reproduction depending on its condition. By this, Husserl explicitly illustrates the different mode of the accomplished re-presentation or recollection as saying thus: Now recollection can occur in different forms of accomplishment. Either we execute it in a simple grasping, as when a memory "rises to the surface" and we look at what is remembered in a flash. In this case what is remembered is vague; perhaps the memory brings forward, intuitively, a privileged momentary phase, but is does not repeat its object. Or we execute a memory that tactually does reproduce and repeat, a memory in which the temporal object is completely built up afresh in continuum of representations and it which we perceive it again, as it were - but only "as it were"

Regarding the massage mentioned above, the re-presentation of the tone has produced two kinds of accomplishments; each of them makes a strong effect to further percept. The former reproduced tone is to look a flash and grasp the remembered tone soon it arises to the surface without repeating its objects. As a consequence, the reproduced tone turns to be vague in this regard. And the reproduced tone as such cannot be perceived resulting in not even constituting in primary memory or retention. By contrast, the latter, after having accomplished recollective modification, repeats and reproduces a memory, the remembered tone, so that the object is completely built up afresh in the continuum and also is perceived again consequently.

\section{Condition of Reproduction}

The modification of mental process in the operation of ideally inherent transformation of the original mental process is to usually deal with the mental process that is related various kinds of factors. Regarding the modification, initially, it starts with original mental process in which the perception of a physical thing as its primal impression in actually perception relates to inherently mental act such as all rememberings, presentations, in phantasy and so on. So, in the terms of perception of mental process, it is separately divided into two sides; one is physical perception which is the perception related to physical things outwardly; other is inner perception which is the perception dealing with the mental process and its immanent data only. So, the reproductive modification is conditioned under both the process of physical perception and immanent perception in this regard.
By the condition of the perception of physical things, the sensuous contents are to be fully perceived depending on two conditions:

1) The condition of the constitution of intuited things: It is about the relation of the perceived

objects and the illuminating circumstances. Although, the objects have the same and one form, maintaining one identical form, they appear with different colors while appearing under an illuminating body; their color appearance does not accurate with their real color appearance. By the contrary, the color appearance of the objects turns to be normal if they are normally seen in the sunlight on the clear sky without any influence of other bodies that might affect the color-appearance.

2) The change of body and change in things: it is relation between body and a thing in perception;

for example, seeing immediately or seeing without any mediating things. By this seeing, it will produce the normal experiences as perceiving the world as it originally constitutes. But if the foreign medium is interposed between eyes and the things seen, the things seen through the foreign medium appear same, but the appearance of the seen things does not accurate with the seen as they are, it is just the appearance of phantom. Another condition related to this point is the case of an abnormal change of an organ itself. In the case of touching, if the object is touched by a finger with a blister or a braded hand, it differently affects to the tactual properties that all the tactual properties of the thing are given differently. Also, in the case of crossing eyes or fingers, the things of sight or things of touch will be two different senses. In addition, with regard to the abnormality of the living body concerning the consumption, especially about medicine. Definitely, some kind of medicine can make a strong effect to body after consuming. This point, Husserl precisely illustrates by exemplifying the santonin. Because of the influence of santonin, it can change the appearance of the world which is the alteration of world's colors as Husserl said, "If I ingest santonin, then the whole world "seems" to change; etc., it "alters" its color. The "alteration" is a "seeming."

By the condition of immanent perception, it is about the condition of the operative transformation based on the inherent modification that mental process flows away with its contents, the immanent contents, related to its temporal phase. As a matter of fact, the process of reproduction is involved in mental process and immanent data that perform the function in the mode of streaming within inner time throughout the phase of perception. By this, the data are immanently modified in each phase of the perception and always flow along with the stream of consciousness which is performing the duty of representation of the data. By this, it creates the level of more or less clear fashion of what is represented. Accordingly, the level of either clarity or obscurity pertaining to reproduction concerns the whole objects that are re-presented and mode of consciousness; they are in the process of the flowing modification from retention to representation respectively. Husserl explains an effect of the flowing modification to the re-presented objects by saying, "In the case of the original givenness of a temporal object, we also found that the object at first appears clearly and vitally and then with diminishing clarity passes over into emptiness. These modifications belong to 
the flow." With this, it results in an obscurity of the represented objects; though, the clear fashion stands before us, but, as if they were seen though a veil, they are more or less obscurity, etc.

Other condition in this point is really concerned with the flow of experiences related to the order of succession. For example, in the case of reproduction of the more distant past, we remember something experienced yesterday, then, produce the event experienced yesterday thereby following all the step of its succession. Here is called the flow of experiences. Anyways, an error would occur from such this way of reproduction. The reproduction brings a past temporal flow to presentation, the individual step of the memorially present event can deviate from those of the past event.

\section{Conclusion}

To investigate the mental process is quite complicated as it functions with various aspects and completed systems. As Husserl forthrightly guarantees that the rational knowledge can be found from pure phenomenon that is to immanently find out whatever flowing under the stream of mental process. So, he tries to find out the way to systematical function of mental process that flows away with its contents called immanent data, which is called pure data. So, to investigate the mental process is to observe the way in which the mental process operates transformation inherently thereby modifying itself with its data. The inherent operative transformation of ideally original mental process is the process of unifying a form of all mental process within one stream of mental process of pure ego. It is the function of mental process functioning with the following aspects: (1) The mode of giveness (the immanent essence of a concrete sensation-content such as a visual sensation-content in the field of visual sensation-Data continually adumbrated from the visual physical object), (2) the temporal mental processes are to be unified as one stream of mental process, (3) the phase or the temporal horizon which is cosmic time in other ways such as horizon of Now, horizon of Before, and horizon of After, and (4) pure ego, the function of which is to direct its regards to the temporal modes of giveness (immanent essences). All of these aspects operate thereby succeeding from the initial. In the process of the operation, it has modified various forms of reproduction such retention, recollection, etc. Moreover, it starts with initial mental process of the physical perception which is called the original mental process succeeding to immanent perception in which the sensuous data are continually used as the succeeding data to a mere mental process as they are kept in mental process; it is called the modification of retention, which is said to be the first memory. By this modification, the mental process changes with its contents and temporal phase from Now-phase of the contents to the new Nowphase. With succeeding from retention, here comes the second memory which is called the modification of recollection. It is the modificative process of the mental process being continually operated thereby succeeding from the retentive modification. It is to recall the contents receded in past as being kept in memory so as to perceive them again as a now phase of the contents for the new experiences. After an accomplishment of the recollection fully, now, the contents of the mental process are reproduced. It reproduces with various forms of reproduction; namely, a flash reproduction and an afresh reproduction; the former is the vague reproduction and the later can produce the remembered. Anyways, the reproduction of the remembered can be fully accomplished depending on the conditions of the perception of physical things and the condition of a level of either clarity or obscurity of the whole objects that are represented and the mode of mental process as the mental process constantly flowing away with its contents and temporal phase might produce either clarity or obscurity of the objects.

\section{References}

[1] Edmund Husserl, Phenomenological Psychology, tr. by John Scanlon, (The Hague: Martinus Nijhoff, 1925), p. 128.

[2] Husserl, Ideas Pertaining to a Pure Phenomenology and to Phenomenological Philosophy: General Introduction to a Pure Phenomenology, First Book, tr. by F. Kersten, (The Hague: Martinus Nijhoff Publishers, 1983), p. 179.

[3] Sense-contents are the data which are the primary one such as the data of colour, touch and sound. The qualities of the object such as the qualities of its colour, its roughness, etc., are the phases of the object which are revealed through sensecontents. Besides, Sense-contents are the layer which gives meaning and the material for the formation of meaning at different levels. For more details, see Bhadra, A Critical Survey of Phenomenology and Existentialism, pp. 66-67.

[4] Husserl, Idea Pertaining to a Pure Phenomenology and to A Phenomenological Phenomenology: General Introduction to A Pure Phenomenology, tr. F. Kersten, (The Hague: Martinus Nijhoff Publishers, 1983), pp. 76-77.

[5] Husserl, Phenomenological Psychology, tr. John Scanlon, (The Hague: Martinus Nijhoff, 1977), p.116.

[6] Husserl, Idea of Phenomenology, (Dordrecht: Kluwer Academic Publishers, 1995), pp. 15-16 
[7] Husserl, Idea Pertaining to a Pure Phenomenology and to A Phenomenological Phenomenology: Studies in the Phenomenology of Constitution, tr. Richard Rojcewicz and Andre Schuwer, (Dordrecht: Kluwer Academic Publishers, 2000), p. 61.

[8] Husserl, Logical Investigation, II, tr., J.N. Findlay, (New York: The Humanities Press, 1970), p. 852.

[9] Husserl, The Paris Lectures, tr. Peter Koestenbaum, (Dordrect: Kluwer Academic Publishers, 1967), p. 18.

[10] Husserl, Phenomenological Psychology, tr. John Scanlon, (The Hague: Martinus Nijhoff, 1977), p. 153.

[11] Husserl, Phantasy, Image Consciousness, and Memory, tr. John B. Brough (Dordrecht: Springer, 2006), p. 636.

[12] Husserl, The Idea of Phenomenology, tr. Lee Hardy, (Dordrecht: Kluwer Academic Publishers, 1999), p. 49.

[13] Husserl, On the Phenomenology of the Consciousness of Internal Time, tr. John Barnett Brough, (Dordrecht: Kluwer Academic Publishers, 1991), p. 100.

[14] Ibid., pp. 100-101.

[15] Ibid., p. 100.

[16] Ibid., p. 24.

[17] Husserl differentiates Hyletic data from physical data completely; color-data, touch-data, tone-data, and the like are sensuous-data or Hyletic data; as for the physical data, it appears with physical manners such as coloredness, roughness, etc.

[18] The terms "primal impression" is the technical terms used by Husserl so as to explain the operates with a moment of the concrete act that is narrowly directed toward the now-phase of the object. See Dan Zahavi, Husserl's Phenomenology, (California: Stanford University Press, 2003), p. 83.

[19] Husserl, On the Phenomenology of the Consciousness of Internal Time, tr. John
Barnett Brough, (Dordrecht: Kluwer Academic Publishers, 1991), p. 31.

[20] Ibid.

[21] Ibid., p. 30.

[22] Husserl, Cartesian Meditations: An Introduction to Phenomenology, tr. Dorion Cairns, (The Hague: Martinus Nijhoff Publishers, 1960), p.102.

[23] See Dan Zahavi, Husserl's Phenomenology, (Stanford: Sandford University Press, 2003), p. 83.

[24] Husserl, Phantasy, Image Consciousness, and Memory, tr. John B. Brough, (The Netherlands: Springer, 2005), p. 37.

[25] Husserl, On the Phenomenology of the Consciousness of Internal Time, tr. John Barnett Brough, (Dordrecht: Kluwer Academic Publishers, 1991), p. 38.

[26] Husserl, Phantasy, Image Consciousness, and Memory, tr. John B. Brough, (The Netherlands: Springer, 2005), p. 670.

[27] As for the terms of "Retention", it produces no enduring objectivities (either originally or reproductively) but only holds in consciousness what has been produced and stamps on it the character of the "just past". See Edmund Husserl, Phantasy, Image Consciousness, and Memory, tr. John B. Brough, (The Netherlands: Springer, 2005), p. 38.

[28] Ibid.

[29] Husserl, On the Phenomenology of the Consciousness of Internal Time, tr. John Barnett Brough, (Dordrecht: Kluwer Academic Publishers, 1991), p. 38.

[30] Ibid.

[31] Ibid.

[32] In the terms of Abnormal organ", it loses its normal psychophysical conditionality together with its normal form, and all things are perceived by such an organ appearing in another aspects, not normal ones. See Husserl, Ideas Pertaining to a Pure Phenomenology and to a Phenomenological philosophy, Second Book, Studies in the Phenomenology of 
Constitution, tr. Richard Rojcewicz and Andre Schuwer, (Dordrecht: Kluwer Academic Publishers, 2002), p. 77.

[33] Santonin is a white crystalline substance having a bitter taste, extracted from the buds of levant, wormseed and used as an anthelmintic. It occasions a peculiar temporary color blindness, causing object to appear as if seen through a yellow glass. Santonin is Anthelmintic isolated from the dried unexpanded flower heads of Artemisia maritime and other species of Artemisia found principally in Russian and Chinese Turkestan and the Southern Ural region. See http://www.definitionof.net/santonin.

[34] Husserl, Ideas Pertaining to a Pure Phenomenology and to a Phenomenological philosophy, Second Book, Studies in the Phenomenology of Constitution, tr. Richard Rojcewicz and Andre Schuwer, (Dordrecht: Kluwer Academic Publishers, 2002), p. 67.

[35] Ibid., p. 50.

[36]

Ibid.

[37] Ibid., p. 51 